\title{
Imaging for Diagnosis, Monitoring, and Outcome Prediction of Large Vessel Vasculitides
}

\author{
Valentin Sebastian Schäfer ${ }^{1} \cdot$ Lei Jin ${ }^{1} \cdot$ Wolfgang Andreas Schmidt ${ }^{3}$ \\ Published online: 21 September 2020 \\ (C) The Author(s) 2020
}

\begin{abstract}
Purpose of Review To discuss and summarize the latest evidence on imaging techniques in giant cell arteritis (GCA) and Takayasu arteritis (TAK). This is a report on the performance of ultrasound (US), magnetic resonance imaging (MRI), computed tomography (CT), 18F-fluorodeoxyglucose positron emission tomography (18-FDG-PET), and other emerging imaging techniques in diagnosis, outcome prediction, and monitoring of disease activity.

Recent Findings Imaging techniques have gained an important role for diagnosis of large vessel vasculitides (LVV). As signs of vasculitis, US, MRI, and CT show a homogeneous arterial wall thickening, which is mostly concentric. PET displays increased FDG uptake in inflamed artery walls. US is recommended as the initial imaging modality in GCA. MRI and PET/CT may also detect vasculitis of temporal arteries. For TAK, MRI is recommended as the first imaging modality as it provides a good overview without radiation. Extracranial LVV can be confirmed by all four modalities. In addition, MRI and PET/CT provide consistent examination of the aorta and its branches. New techniques such as contrast-enhanced ultrasound, PET/MRI, and auxiliary methods such as "computer-assisted quantitative analysis" have emerged and need to be further validated.

Summary Imaging has partly replaced histology for confirming LVV. Provided experience and adequate training, US, MRI, CT, or PET provide excellent diagnostic accuracy. Imaging results need to complement history and clinical examination. Ongoing studies are evaluating the role of imaging for monitoring and outcome measurement.
\end{abstract}

Keywords Giant cell arteritis · Takayasu arteritis · Imaging · Diagnosis · Outcome · Large vessel vasculitis · Ultrasound · Magnetic resonance imaging $\cdot$ Computed tomography $\cdot 18 \mathrm{~F}$ - fluorodeoxyglucose positron emission tomography

\section{Introduction}

Giant cell arteritis (GCA) and Takayasu arteritis (TAK) are granulomatous large vessel vasculitides (LVV). They are associated with considerable morbidity. Vision loss is common in GCA if initiation of treatment is delayed. Strokes and

Valentin Sebastian Schäfer and Lei Jin contributed equally to this work.

This article is part of the Topical Collection on Recent Advances in Large Vessel Vasculitis

Valentin Sebastian Schäfer

valentin.s.schaefer@hotmail.de

1 Department of Rheumatology and Clinical Immunology, Clinic of Internal Medicine III, University Hospital Bonn, Bonn, Germany

2 Immanuel Krankenhaus Berlin, Medical Centre for Rheumatology Berlin-Buch, Berlin, Germany occlusions may occur in both GCA and TAK. Early diagnosis is crucial. Compared with histology, imaging is non-invasive, and results are readily available.

Similar clinical, histopathologic, and imaging features suggest that they are somewhat related. Otherwise, GCA and TAK differ in terms of age of onset (GCA $\geq 50$ years, TAK most commonly $\leq 40$ years), sex predominance (females even more commonly affected in TAK than in GCA), distribution of arterial lesions, treatment, and prognosis. Histopathology shows granulomatous inflammation [1], and imaging of extracranial arteries often displays involvement of the aorta and its branches in both entities [2-4]. Differentiating between GCA and TAK is important, as recent studies have shown different treatment responses in GCA and TAK to the same biologic therapies [5, 6], indicating the importance of correct diagnosis. This will affect the treatment regime and subsequently the prognosis.

The age at onset is an important feature to distinguish these two diseases. TAK occurs before 40 to $<50$ and GCA with $\geq$ 
50 years of age [3]. The temporal arteries are never affected in TAK. The axillary arteries are more commonly involved in GCA. The carotid and subclavian arteries are more commonly involved in TAK [7].

Temporal artery biopsy (TAB) has been the diagnostic gold standard for decades for confirmation of GCA, but it is invasive and lacks sensitivity with false-negative test results in up to $60 \%$. Results may further be falsenegative due to skip lesions or limitation of GCA to extracranial arteries. Furthermore, results are mostly available not earlier than 1 week after GCA has been suspected. It could be shown that the net monetary benefit was $£ 485$ per patient in favor of ultrasound (US) when compared with $\mathrm{TAB}$ as the first diagnostic test [8]. Obtaining a biopsy in TAK is impossible in most cases due to the predominant involvement of extracranial arteries. If surgery is necessary due to stenosis, occlusion, or aneurysms, it should be attempted in every case to harvest material from arteries for histological examination. As the diagnosis can be reliably confirmed by imaging, imaging has increasingly become the first-line diagnostic test for confirmation of GCA and TAK [2].

The role of different imaging modalities including US, magnetic resonance imaging (MRI), computed tomography (CT), and 18F-FDG positron emission tomography (18FDG-PET) in LVV has been addressed in several studies over the last years. A European League Against Rheumatism (EULAR) project has therefore been undertaken to develop recommendations for the use of imaging in LVV in clinical practice [9].

Ultrasound-guided fast-track clinics for patients with suspected GCA have been introduced. Physicians can contact centers offering these clinics. Patients will receive an appointment within $24 \mathrm{~h}$ during the week. Rheumatologists experienced in GCA perform a structured history and clinical examination. This is directly followed by a US exam of at least the temporal and axillary arteries, preferably by the same rheumatologist. The incidence of vision loss significantly decreased after the introduction of such fasttrack clinics [10-12]. Based on these and other considerations, the importance of imaging modalities has steadily increased [13, 14].

Ultrasound, CT, PET/CT, and MRI are increasingly applied. Older studies used angiography. Angiography however carries risks of allergic reactions, hematoma, iatrogenic embolisation, and arterial dissection, and it does not display the inflamed arterial wall itself. Therefore, modern imaging methods have almost replaced angiography unless it is performed for therapeutic vascular interventions [15]. EULAR recommendations for the use of imaging in LVV in clinical practice have been published, in which recommendations for each imaging modality were given [9].
The aim of this review is to discuss and summarize the latest evidence on different imaging modalities in diagnosis, outcome prediction, and monitoring of disease activity in both GCA and TAK.

\section{Methods}

A literature review was conducted using PubMed, Embase, and Cochrane databases from March 2015 to March 2020. Search termini were Takayasu arteritis, giant cell arteritis, imaging, magnetic resonance imaging, computed tomography, 18F-FDG positron emission tomography, contrast-enhanced ultrasound, ultrasound, positron emission tomography/ magnetic resonance imaging, large vessel vasculitis, outcome, and prognosis. Papers were included by clinical relevance.

\section{Imaging in Diagnosis of Giant Cell Arteritis and Takayasu Arteritis}

\section{Ultrasound}

US can be performed simultaneously with history taking and clinical examination by the clinician and is widely used in European countries by now. Spatial resolution is very high, $0.1 \mathrm{~mm}$ with $20 \mathrm{MHz}$ transducers and even $0.03 \mathrm{~mm}$ with $70 \mathrm{MHz}$ transducers [16] in superficial anatomical structures such as the temporal arteries. This allows delineation of the intima-media complex (IMC) [17].. The mean intima-media thickness (IMT) in temporal and axillary arteries is $0.2 \mathrm{~mm}$ and $0.6 \mathrm{~mm}$, respectively, in a population of 70-year-old patients. The cut-off value for distinguishing normal from vasculitic arteries is about $0.4 \mathrm{~mm}$ for temporal arteries and $1.0 \mathrm{~mm}$ for axillary arteries [18]. The "halo" and the "compression" signs are regarded as the most important US abnormalities for cranial GCA (Tables 1 and 2). The halo sign is defined as "homogenous, hypoechoic wall thickening, well delineated towards the luminal side, visible both in longitudinal and transverse planes, most commonly concentric in transverse scans" [18] (Fig. 1). The compression sign means that "the thickened arterial wall remains visible upon compression; the hypoechogenic vasculitic vessel wall thickening contrasts with the mid-echogenic to hyperechogenic surrounding tissue" [27]

The inter-rater and intra-rater agreement of images and videos applying the above-mentioned definitions was excellent, with mean kappa values of $0.83-0.98$ for both inter-rater and intra-rater reliabilities [27]. In the TABUL study, a study to compare the diagnostic value of US with that of biopsy, readers of US images and videos obtained the same reliability as pathologists evaluating TAB specimen [8]. Further, it was shown in a live exercise on patients that these definitions are reliable in recent-onset GCA, if experienced sonographers (> 
Table 1 Definition of vasculitis in giant cell arteritis and Takayasu arteritis in different imaging modalities

\begin{tabular}{|c|c|c|}
\hline $\begin{array}{l}\text { Imaging } \\
\text { modality }\end{array}$ & Giant cell arteritis & Takayasu arteritis \\
\hline \multirow[t]{4}{*}{ US } & _ "Halo sign” & - "Macaroni sign" \\
\hline & - "Compression sign" & Sensitivity $81 \%$ \\
\hline & Sensitivity: 77 & Specificity of $>90 \%[20]$ \\
\hline & $\begin{array}{l}\text { Sensitivity: } 96[19] \text { (clinical diagnosis of GCA as the } \\
\text { reference standard) }\end{array}$ & (clinical diagnosis of GCA as the reference standard) \\
\hline \multirow[t]{3}{*}{ CTA } & $\begin{array}{l}\text { - Mural thickening and enhancement, late contrast uptake } \\
\text { - Vascular stenosis/occlusion/ectasia } \\
\text { - Surrounding edema/tissue reaction }\end{array}$ & Same as for GCA \\
\hline & Sensitivity $84.6 \%$ & Sensitivity $100 \%$ \\
\hline & $\begin{array}{l}\text { Specificity } 84.6 \% \text { [21] (clinical diagnosis of GCA as the } \\
\text { reference standard) }\end{array}$ & Specificity $100 \%$ [22] (conventional angiography as the reference standard) \\
\hline \multirow[t]{6}{*}{ MRA } & - Mural thickening and enhancement & Same as for GCA \\
\hline & - Vascular stenosis/occlusion/ectasia & + Carotid artery involvement: branches of the internal carotid artery more \\
\hline & - Surrounding edema/tissue reaction & common [23] \\
\hline & $\begin{array}{l}\text { - Carotid artery involvement: branches of the external } \\
\text { carotid artery more common [23] }\end{array}$ & \\
\hline & Sensitivity $73 \%$ & Sensitivity $100 \%$ \\
\hline & $\begin{array}{l}\text { Specificity } 88 \% \text { [24] (clinical diagnosis of GCA as the } \\
\text { reference standard) }\end{array}$ & Specificity $100 \%[25]$ (conventional angiography as the reference standard) \\
\hline \multirow[t]{8}{*}{ FDG/PET } & - Mural thickening and tracer uptake & Same as for GCA \\
\hline & - Vascular stenosis/occlusion/ectasia & + Left subclavian artery together with bilateral involvement of the carotid \\
\hline & - Surrounding edema/tissue reaction & arteries and the mesenteric arteries [23] \\
\hline & - Cluster analysis of involved arteries & \\
\hline & GCA specific: & \\
\hline & $\begin{array}{l}\text { - Symmetric subclavian artery with concomitant axillary } \\
\text { artery vasculitis }\end{array}$ & \\
\hline & Sensitivity $92 \%$ & Sensitivity $81 \%$ \\
\hline & Specificity $85 \%$ [26] (TAB as reference standard) & $\begin{array}{l}\text { Specificity } 74 \% \text { [20] (clinical criteria and/or angiography as the reference } \\
\text { standard) }\end{array}$ \\
\hline
\end{tabular}

US ultrasound, CTA computed tomography angiography, MRA magnetic resonance angiography, FDG/PET fluorodeoxyglucose positron emission tomography

300 examinations) have 15-20 min for a standardized examination with prior training and application of $>15 \mathrm{MHz}$ probes [28]. The main disadvantage of US is its limited ability to assess the thoracic aorta except for transesophageal echocardiography.

Ultrasound in Giant Cell Arteritis A standardized US examination in GCA should include at least the temporal and axillary arteries. Adding the examination of axillary arteries increases the diagnostic yield of US for the diagnosis of GCA [29]. In a recently published study, the sensitivity increased from 71 to $97 \%$ when additionally examining the carotid and axillary arteries to the temporal arteries. Further arteries may be examined if the clinical diagnosis is not yet clear. Another imaging technique such as PET-CT is only needed if the diagnosis is still not confirmed or excluded after the US examination [30].

Ultrasound of Temporal and Axillary Arteries US depicts a normal arterial IMC as a homogeneous, hypoechoic (dark), or anechoic (black) structure delineated by two parallel hyperechoic margins [27]. The definition of the "halo sign"
[31] is given above (Figs. 1 and 2). Cut-off values for the intima-media thickness (IMT) can differentiate normal from vasculitic patients with high sensitivities and specificities [24, 32, 33]. The specific cut-off values are $0.42 \mathrm{~mm}, 0.34 \mathrm{~mm}$, $0.29 \mathrm{~mm}, 0.37 \mathrm{~mm}$, and $1.00 \mathrm{~mm}$ for the common superficial temporal arteries, the frontal and parietal branches, the facial arteries, and the axillary arteries, respectively [18].

Sundholm et al. [16] reported that they were able to distinguish the intima from the media in GCA and control subjects with a cut-off value for intima thickness of $0.06 \mathrm{~mm}$ when using a $55 \mathrm{MHz}$ probe. They compare their findings with histology taken from the same anatomic area. Further research for very high-resolution US probes in the diagnosis of GCA is necessary.

A meta-analysis found a high specificity of $96 \%$ for US in diagnosis of GCA [24]. The halo sign of temporal arteries has been described in few patients with other diseases such as amyloidosis, atherosclerosis, and ANCAassociated vasculitides with temporal artery involvement [34]. These cases teach us the importance of history and clinical examination in connection with US in every patient with suspected GCA [35]. 
Table 2 Advantages and Disadvantages of different imaging modalities

\begin{tabular}{|c|c|c|}
\hline Imaging modality & Advantages & Disadvantages \\
\hline Ultrasound & $\begin{array}{l}\text { - Widely available } \\
\text { - Patient friendly and repeatable } \\
\text { - Short acquisition time, approx. } 15 \mathrm{~min} \\
\text { - Feasible for fast-track clinics } \\
\text { - Cheaper than other imaging techniques or biopsy } \\
\text { - Very high resolution (up to } 0.1 \mathrm{~mm} \text { in superficial } \\
\text { anatomical structures) } \\
\text { - High evidence level in LVV }\end{array}$ & $\begin{array}{l}\text { - Limited ability to assess the thoracic and abdominal } \\
\text { aorta } \\
\text { - Limited overview of involved vessels }\end{array}$ \\
\hline Computed tomography angiography & $\begin{array}{l}\text { - Good overview of the aorta and its branches } \\
\text { - Different contrast phases can display vasculitis } \\
\text { - Good delineation of atherosclerotic plaques } \\
\text { - Relatively fast acquisition time }\end{array}$ & $\begin{array}{l}\text { - Radiation, approx. } 17 \mathrm{mSv} \\
\text { - Contract agent cannot be used in reduced kidney } \\
\text { function }\end{array}$ \\
\hline Magnetic resonance angiography & $\begin{array}{l}\text { - Delineates the typical arterial pathology in LVV } \\
\text { - Excellent overview of involved arteries } \\
\text { - Multiple cranial and extracranial arteries can be } \\
\text { investigated simultaneously } \\
\text { - Superior to ultrasound for examining the aorta } \\
\text { - Does not require ionizing radiation or iodinated contrast } \\
\text { agents }\end{array}$ & $\begin{array}{l}\text { - Less sensitive than CT and ultrasound in detecting } \\
\text { calcifications } \\
\text { - More expensive than ultrasound but less expensive } \\
\text { than PET/CT } \\
\text { - Claustrophobia, cardiac pacemakers, or other } \\
\text { mobile-implanted metal devices } \\
\text { - Long acquisition time } \\
\text { - Few centers with expertise in diagnosis for cranial } \\
\text { GCA }\end{array}$ \\
\hline $\begin{array}{l}\text { Positron emission tomography with } \\
\text { computed tomography }\end{array}$ & $\begin{array}{l}\text { - Excellent overview of involved arteries } \\
\text { - Ability to detect pathology in differential diagnoses of } \\
\text { LVV like infection or malignancy } \\
\text { - Potentially more sensitive than MRI to detect activity in } \\
\text { follow-up } \\
\text { - High evidence level in LVV }\end{array}$ & $\begin{array}{l}\text { - Radiation of about } 25 \mathrm{mSv} \\
\text { - Expensive } \\
\text { - Not possible if glucose concentration is elevated } \\
\text { - Sensitivity considerably decreases after }>3 \text { days } \\
\text { - Atherosclerosis may be misinterpreted as LVV } \\
\quad \text { particularly in the femoral arteries }\end{array}$ \\
\hline
\end{tabular}

Ultrasound Findings in Other Cranial Arteries The facial arteries are easily accessible at the level of the mandible. The occipital arteries are located posteriorly to the mastoid. Facial and occipital vasculitis has been detected by US in $41 \%$ and $31 \%$ of patients with GCA, respectively. More patients with facial arteritis had jaw claudication ( $71 \%$ versus $27 \%$ ) and permanent blindness (24\% versus $2 \%$ ) compared with GCA patients without facial arteritis. Vasculitis of facial or occipital arteries usually occurred together with vasculitis of temporal arteries [36] and should be visualized, if ultrasound findings of temporal and axillary arteries are inconclusive.

Ultrasound Findings in Other Extracranial Arteries The subclavian, common carotid, and vertebral arteries can be easily examined with US. In GCA, these arteries are at most affected in conjunction with temporal or axillary arteries. It is worth noting that carotid artery stenosis is rarely caused by GCA [37]. Depending on further symptoms, many other arteries like the abdominal aorta, coeliac and mesenteric arteries, and femoral and popliteal arteries are accessible by US. Aschwanden et al. [38] described vasculitic findings in 37 of 68 GCA patients in PET/CT and US, while 11 of 68 had positive findings only in US and 14 of 68 in PET/CT only. Authors concluded that $\mathrm{PET} / \mathrm{CT}$ and US should be considered as complementary methods, with a second imaging modality increasing the diagnostic yield by $16-20 \%$.

Ultrasound in Takayasu Arteritis In TAK, the US image is similar to GCA. The thickened artery wall appears most commonly more hyperechoic, as TAK is often diagnosed late when chronic changes are already prevalent (Fig. 3). Maeda $\mathrm{H}$ et al. [39]described in 1991 the "macaroni sign," defined as characteristic circumferential arterial wall thickening of either one or both sides of the common carotid arteries, as a disease indicator for Takayasu arteritis. The "macaroni sign" is similar to the "halo sign" an indicator of an inflamed vessel wall with increased IMT.

TAK most commonly affects the left subclavian and common carotid arteries. In suspected disease, the carotid, subclavian, and vertebral arteries should be examined by US together with the abdominal aorta. In case of arterial hypertension, the renal arteries should be additionally examined. A metaanalysis on US in TAK reported a sensitivity of $81 \%$ and a specificity of $>90 \%$ for TAK diagnosis compared with clinical criteria and/or routine angiography [20].

\section{Magnetic Resonance Imaging}

The main advantage of MRI, which may be performed with contrast agents, is its excellent overview of involved arteries, 


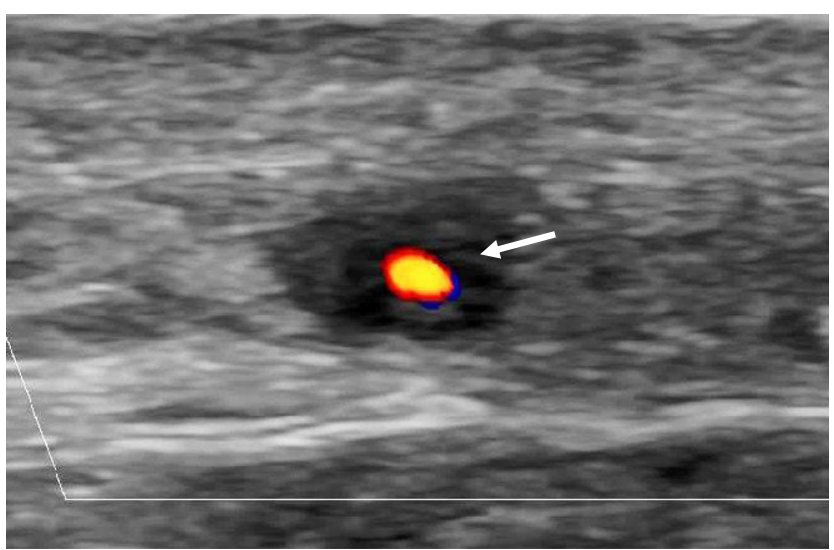

Fig. 1 Halo sign of the common superficial temporal artery. Typical halo sign of the common superficial temporal artery, transverse scan, in a patient with newly diagnosed GCA

therefore named magnetic resonance angiography (MRA). It is free from radiation. With dedicated coils, small arteries like the temporal arteries can be depicted. Its sensitivity to detect calcifications and arterioslerotic plaques is lower compared with CT and US. It cannot be performed in patients with claustrophobia, cardiac pacemakers, or other mobileimplanted metal devices or in the case of chronic kidney disease stage IV or V [40]. Further MRI is limited because of its restricted availability and its costs.

\section{Magnetic Resonance Imaging in Giant Cell Arteritis MRA} provides detailed information about the arterial lumen and wall. The EULAR recommendations on imaging in LVV state that high-resolution MRI of cranial arteries may be used as an alternative for GCA diagnosis if US is not available or inconclusive. It can also be used for examining the extracranial arteries to support the diagnosis of large vessel GCA [9].

A recent meta-analysis [24] summarized 43 prospective studies (39 on GCA, 4 on TAK), six studies compared MRA with the clinical diagnosis of GCA as a reference standard; the pooled sensitivity and specificity were $73 \%$ (95\% CI, 57-85\%) and $88 \%$ (95\% CI, 81-92\%) respectively, for the detection of GCA in MRA. When TAB was used as the reference standard, MRA yielded a sensitivity of $93 \%$ (95\% CI, 89 to 96$)$ and a specificity of $81 \%$ (95\% CI, 73 to 87 ) [24]. Data from this meta-analysis were derived only by two very specialized centers, bearing the risk of considerable bias regarding the value of this technique in general practice. In contrary to previous knowledge, vasculitis may not be limited to extracerebral arteries but may extend to intra-cerebral arteries. Intracranial arteries are, however, not solely involved in GCA [41].

Conventional two-dimensional (2D) black-blood sequences are time-consuming, provide a limited scan area, and cannot be reconstructed in various planes. Thus, vessels which are oriented obliquely cannot be analyzed perpendicularly to their course. Recently, a high-resolution T1w three-



Fig. 2 Vasculitis of the axillary artery in giant cell arteritis (longitudinal view). Longitudinal view of the axillary artery in a patient with large vessel GCA, the intima-media complex is significantly thickened, $1.81 \mathrm{~mm}$; normal $<1.0 \mathrm{~mm}$

dimensional (T1w-3D) fat-suppressed turbo spin echo (TSE) sequence (VISTA volumetric isotropic TSE acquisition) has resolved these limitations. Treitl et al. [42] examined $25 \mathrm{LVV}$ patients with a $3 \mathrm{~T}$ MRA using $1.2 \times 1.3 \times 2.0 \mathrm{~mm}^{3}$ fatsuppressed, T1w-3D, modified volumetric isotropic TSE acquisition (mVISTA) pre- and post-contrast sequences. Authors concluded that navigated fat-suppressed T1w-3D black-blood MRI with PPU-triggering allows diagnosis of thoracic LVV with good reliability results. Unfortunately this technique is not available in routine clinical practice.

Magnetic Resonance Imaging in Takayasu Arteritis The EULAR recommendations propose MRA as the first imaging modality in diagnosis of TAK [9]. This recommendation is almost entirely based on expert opinion and current clinical practice. MRI is a technique without radiation exposure and therefore preferable over other imaging modalities in the rather young TAK patients. MRI enables the assessment of the vessel wall and luminal changes, which are both relevant for TAK, and provides an information on the distribution of vessel involvement. One study comparing MRA with angiography as the reference standard yielded a sensitivity of $98 \%$ and a specificity of $100 \%$ for MRA in TAK [25].

\section{8-Fluorodeoxyglucose Positron Emission Tomography}

18-FDG-PET detects increased glucose metabolism in inflamed arteries. It is most commonly combined with $\mathrm{CT}$ in order to allocate PET findings to a specific arterial segment. PET-CT provides an excellent overview in suspected vasculitis. Particularly in patients with unclear inflammation, PET may detect alternative diagnoses like tumors, lymphoma, or septic foci [43]. PET should be performed not later than 3 days after initiation of glucocorticoid treatment as sensitivity 
considerably decreases. In patients with initially positive PETCT, only $36 \%$ had positive findings after 10 days [20]. PET$\mathrm{CT}$ is however expensive, and radiation exposition is high. Its use is limited with elevated blood glucose levels.

\section{8-FDG Positron Emission Tomography in Giant Cell Arteritis} Until recently, PET was thought to be limited to extracranial arteries. New studies however showed that modern equipment can detect pathology in smaller arteries like temporal, facial, and maxillary arteries $[26,44]$.

In large vessel GCA, the subclavian arteries display most frequently FDG uptake (up to $75 \%$ ), followed by the abdominal and thoracic aorta in approximately $50 \%$, while an increased FDG uptake in the axillary, carotid, iliac, and femoral arteries is seen in $30-40 \%$ [45]. One study arrived at a specificity of $>90 \%$ in the supraaortic arteries but lower specificities for the aorta and the lower extremities (70-80\%). FDG uptake is typically symmetrical in GCA. The specificity of increased FDG uptake in the lower limbs and the abdominal aorta is lower (70$80 \%$ ), because these arteries are more prone to atherosclerosis. As glucose metabolism is increased in the arterial walls in arteriosclerosis, PET can be falsely positive, albeit enhancement is usually less intense in arteriosclerosis.

In a recent study of 64 newly suspected GCA patients, the sensitivity and specificity of PET/CT were $92 \%$ and $85 \%$, respectively, compared with $\mathrm{TAB}$, with a high negative predictive value $[26,46]$. A recent retrospective study evaluated the diagnostic performance of 18-FDG PET-CT for large vessel involvement in patients with suspected GCA and negative TAB [47]. In these 63 patients, 18F-FDG PET-CT showed large vessel involvement in 22 patients, 14 of whom were finally diagnosed with GCA and 41 patients were $18 \mathrm{~F}-\mathrm{FDG}$ PET-CT negative and nine were diagnosed with GCA.

Although the intensity of vascular FDG uptake in GCA declines with glucocorticoid treatment, long-term persistent vascular FDG uptake may be present despite clinical remission [48]. Blockmans D et al. [45] suggested that FDG-PET cannot identify patients at risk of relapse. Arnaud et al. [49] reported a poor correlation between FDG uptake and disease activity in LVV. There are arguments for ongoing subclinical inflammation, but the increased signal may also be ascribed to vascular remodeling as vascular smooth muscle cells also take up FDG [50]. Grayson et al. [51] found a residual FDG uptake in $55 \%$ of patients in clinical remission.

Activated macrophages and $\mathrm{T}$ lymphocytes are fundamental elements in the pathogenesis of GCA and TAK. Recently a new compound PK11195, which has a high affinity with cells of an activated nuclear phagocytic cell line, was tested and was able to visualize vascular inflammation in patients with vasculitis vs. controls. The results were not compared with conventional PET/CT due to radiation (Fig. 4) [52].

\section{8-FDG Positron Emission Tomography in Takayasu Arteritis} Incerti $\mathrm{E}$ et al. [53] prospectively examined 30 patients with TAK by both PET/CT and MRI. The authors concluded that PET/CT reveals unique and fundamental features of arterial involvement and confirmed the role of PET/CT in the assessment of local inflammatory and vascular remodeling during follow-up, even in lesions in which the arterial wall is $<4 \mathrm{~mm}$ in MRI. Soussan M et al. [54] performed a meta-analysis of studies published between January 2000 to December 2013 (21 studies, 413 patients, 299 controls) and retained a sensitivity and specificity of $87 \%$ and $73 \%$, respectively, for discriminating active from inactive TAK.
Fig. 3 Vasculitis of the common carotid artery in Takayasu arteritis. US of the common carotid artery in a patient with Takayasu arteritis. The intimamedia thickness of the common carotid artery is relevantly increased (arrow). Further is the flow velocity increased, indicating a stenosis of about $50 \%$ or decreased elasticity of the wall

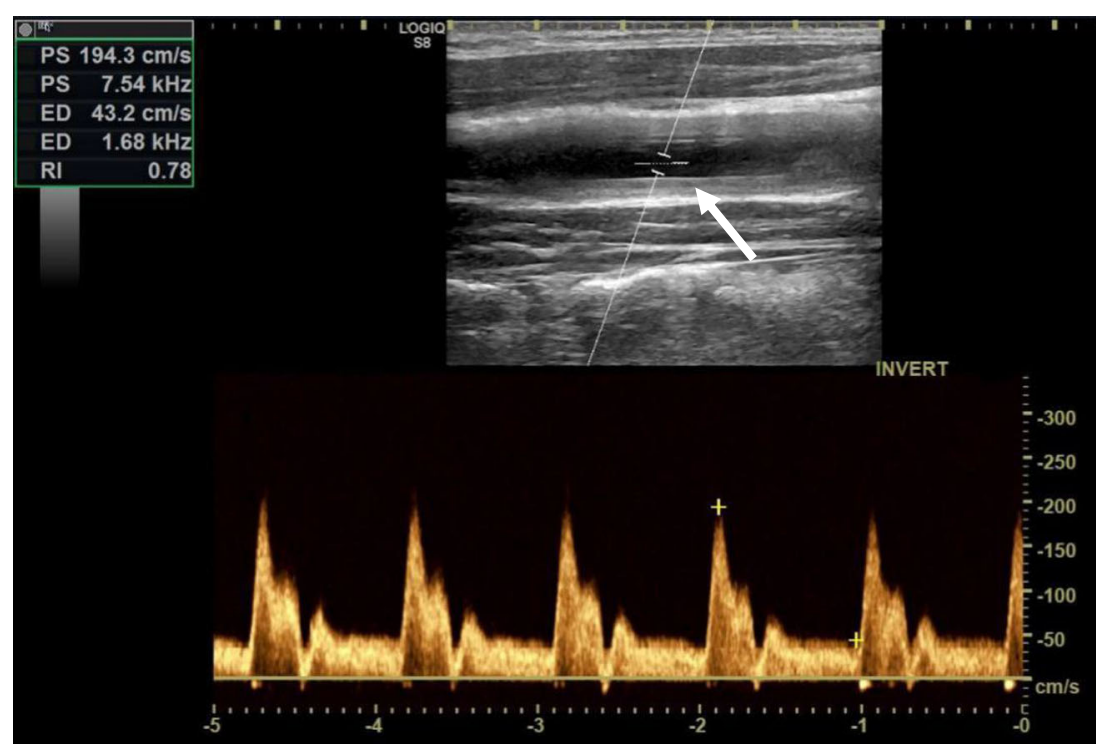



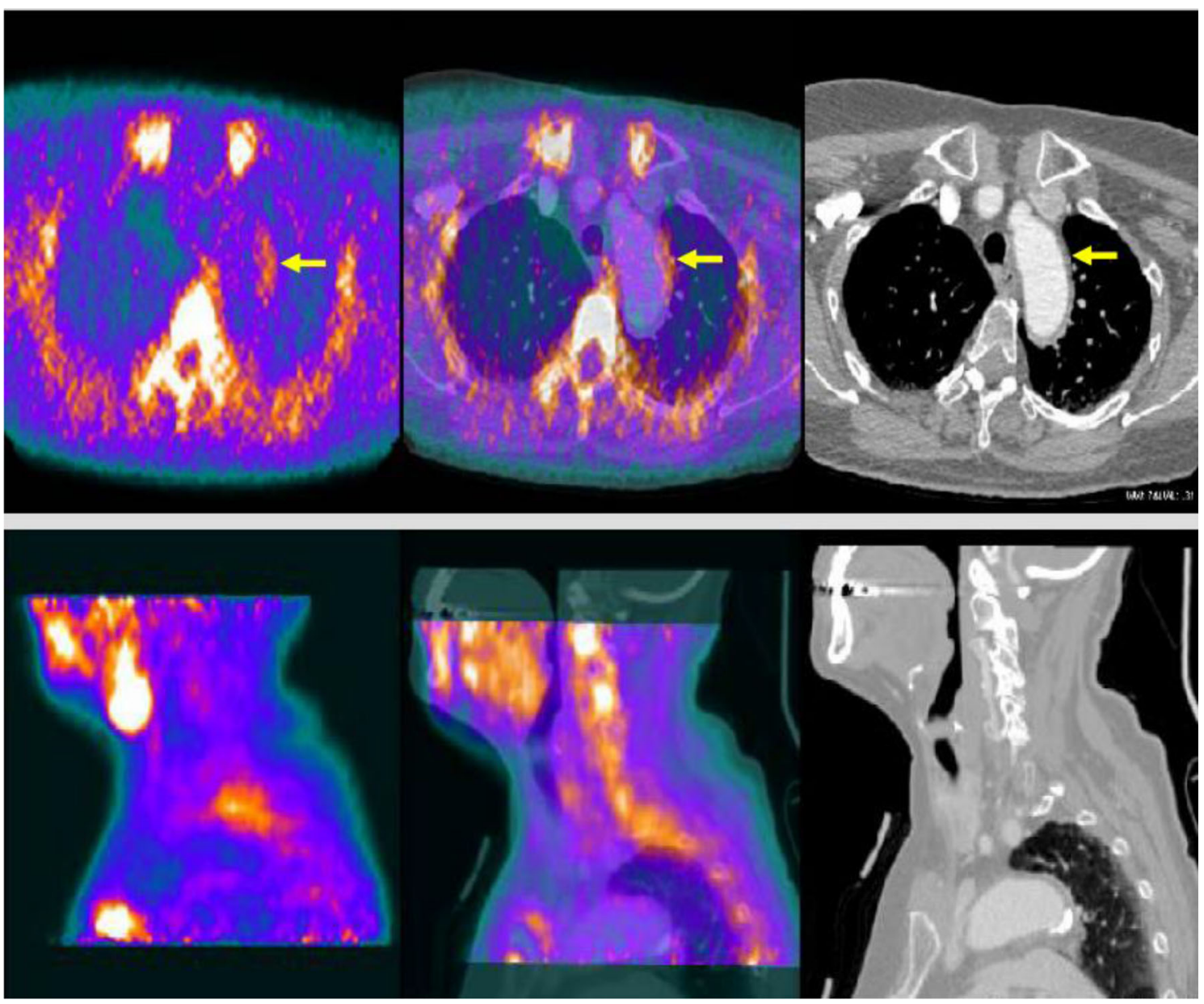

Fig. 4 Hybrid [11C]-PK11195 PET/CT in a patient with giant cell arteritis. Hybrid [11C]-PK11195 PET-CT and CT images. From left to right, fusion image, in the middle is PK11195 and on the right side CT

In a recently published meta-analysis on imaging modalities for the diagnosis and disease activity assessment of TAK, pooled sensitivity of FDG-PET for disease activity was $81 \%$ (95\% CI, 69-89\%) and pooled specificity $74 \%$ (95\% CI, 55$86 \%$ ) [20]. Heterogeneity of PET/CT results could be explained by varying definitions of abnormal thresholds, patient characteristics, and standards for determining disease activity, as there is no gold standard for disease activity.

\section{Computed Tomography Angiography in Giant Cell Arteritis and Takayasu Arteritis}

Computed tomography angiography (CTA), requiring IV application of iodine-based contrast agents, is also a common method used in diagnosis of LVV. Arteritis on CTA presents with mural thickening and double ring enhancement after intravenous injection of iodine-based contrast agent [37]. In a prospective study on 24 patients with suspected GCA, of whom 15 were ultimately diagnosed as GCA on an individual basis by experienced clinicians, mural thickening on CTA had a somewhat lower specificity $(84.6 \%$ versus $100 \%)$ and a images of the same giant cell arteritis patient in transverse and sagittal section. Courtesy of Professor Paolo G. Camici, Milano, Italy

positive predictive value of ( $84.6 \%$ versus $100 \%)$ than an increased FDG uptake on PET scanning, whereas sensitivity reached $73.3 \%$ for CTA and $66.7 \%$ for FDG-PET [21]. De Boysson et al. [55] compared CTA with FDG-PET/CT in a series of 28 patients with GCA. Using FDG-PET/CT as a reference, CTA showed excellent sensitivity (95\%) and specificity $(100 \%)$ in a per-patient analysis. In a per-segment analysis, sensitivity and specificity were $61 \%$ and $97.9 \%$, respectively. Hommada et al. [56] described a perfect agreement between PET and CT at a patient-based level and very good agreement at a vascular segment-based level (kappa, 0.72 to 1). Discrepancies between PET and CT were observed only in relapsing $\mathrm{GCA}(n=3)$.

\section{Other Methods}

\section{Contrast-Enhanced Ultrasound}

Although MRI and CT can reveal signs suggestive of vasculitis, no clear correlation with disease activity or progression 
has been found [13], while utility of PET in the follow-up of patients with LVV is somewhat more debated.

There is a need to develop alternative imaging modalities to assess the arterial inflammation in LVV. Therefore, some authors performed studies on contrast-enhanced ultrasound (CEUS).

In the study of Germanò $\mathrm{G}$ et al. [57], 31 patients (14 with TAK, 17 with CCA) underwent both PET, color Doppler US, and CEUS of the right carotid artery. 18F-FDG uptake was used as the reference standard for vascular inflammation. Carotid CEUS had a sensitivity of $100 \%$ (95\%confidence interval $(95 \% \mathrm{CI}), 65-100)$ and a specificity of $92 \%(95 \% \mathrm{CI}$, 72-99). Ling-Ying Ma et al. [58] compared acute phase reactants and CEUS scans of 84 TAK patients at baseline and after 3 months of therapy. They showed that the combination of CEUS parameters and ESR could help to differentiate between active and inactive TAK by physicians global assessment with a sensitivity and specificity of $81.1 \%$ and $81.5 \%$, respectively [59]. In a study by Lottspeich et al. [60], the carotid CEUS scores decreased sharply in three patients with TAK after tocilizumab treatment. Therefore, CEUS appears to have some potential for assessing disease activity in TAK and during follow-up.

CEUS is able to investigate a limited number of vessels only, due to the short time interval when contrast agent remains at sufficient high concentration in the circulation. Most commonly, the carotid arteries have been examined. The analysis is qualitative, and results may rely on the sonographer's experience. To overcome this deficiency, Hu Yanlu et al. [61] published a computer-assisted quantitative analysis of the carotid artery in TAK based on CEUS. First, the vasculitis lesion was outlined on the carotid wall, and one homogeneous rectangle and one polygon were selected as two reference regions in the carotid lumen. The temporal and spatial features of the lesion region and the reference regions were then calculated. Furthermore, the difference and ratio of the features between the lesion and the reference regions were computed as new features (to eliminate interference factors). Finally, the correlation was analyzed between the CEUS features and inflammation biomarkers consisting of erythrocyte sedimentation rate (ESR) and C-reactive protein (CRP). Further studies are needed to evaluate this new method.

\section{Positron Emission Tomography with Magnetic Resonance Imaging}

Compared with PET-CT (radiation exposure in average approx. $25 \mathrm{mSv}$ ) [62], PET/MRI can reduce the radiation dose for patients by approximately $20 \mathrm{mSv}$, allowing comprehensive and multimodal analysis of vascular wall inflammation and vascular lumen. It offers promising perspectives for evaluating the disease activity during follow-up.
Both for GCA and TAK, repeated PET/MRI might help to identify relapse, progression of damage, and development of aneurysms. Additionally, MRI allows the analysis of vascular arterial gadolinium uptake as an additional marker of vascular inflammation (Figs. 5 and 6) [63].

Einspieler I et al. [64] performed PET/MRI and PET/CT in 12 LVV patients, 2 with TAK, and 10 with GCA. They compared the visual scores and quantitative parameters (maximum standardized uptake value (SUVmax) and target to background ratio) between the two methods. Authors did not find a significant difference between both modalities concerning these parameters.

In a recent retrospective study, 14 patients with aortitis (11 active GCA, 3 acitive TAK) and 14 patients with suspected active LVV underwent 18F-FDG for the evaluation of inflammatory aortic involvement. All patients were imaged with a $3 \mathrm{~T}$ MRI with T1W VIBE pre- and post-contrast sequences in order to compare these two imaging techniques. T1W VIBE MRI of the aorta detected vessel wall inflammation in a comparable number of patients with LVV compared with $18 \mathrm{~F}$ FDG PET [65]. In the retrospective study of Laurent et al. [63], 13 patients who underwent 18 PET/MRI scans (TAK, $n=10$ scans; GCA, $n=8$ scans) at diagnosis $(n=4)$, relapse $(n=7)$, or during remission $(n=7)$, compared PET/MRI imaging with clinical symptoms and outcome, concluded that PET/MRI was highly linked to disease activity, particularly in TAK.

\section{Outcome Prediction and Monitoring of Disease Activity and Damage}

The lack of standardized outcome measures is problematic in the design and interpretation of clinical trials. Generic instruments like the Birmingham Vasculitis Activity Score have limitations in GCA [66], while the Indian ITAS may be helpful in TAK [67]. An international collaborative effort is underway to address this [68]. EULAR recommendations have been published for a core data set to support observational research and clinical care in GCA [69]. In a Delphi survey of international experts in LVV from different specialties, $22 \%$ stated that GCA and TAK were unsuitable for common outcome parameters [70]. The role of imaging in monitoring of disease activity in GCA and TAK is still a matter of further research.

\section{Ultrasound}

The role of US in monitoring disease activity is currently studied. With treatment, the echogenicity of the artery walls increases, while IMT decreases. While US abnormalities normalize rapidly in temporal arteries, residual wall swelling in 
Fig. 5 PET/MRI in a patient with giant cell arteritis. PET/MRI shows an inflammatory pattern with clear uptake (> liver uptake, grade 3) in vertebral arteries. a Maximum intensity projection and $\mathbf{b}$ fusion MR angiography/ PET (arrows) associated with arterial wall thickening on: (c) MR axial T2-weighted image and (d) T2-weighted/PET fusion. Arrows indicate vertebral artery. Laurent C et al. Sci Rep. 2019 Aug 27;9(1):12388 [63] published under a CC BY 4.0 license
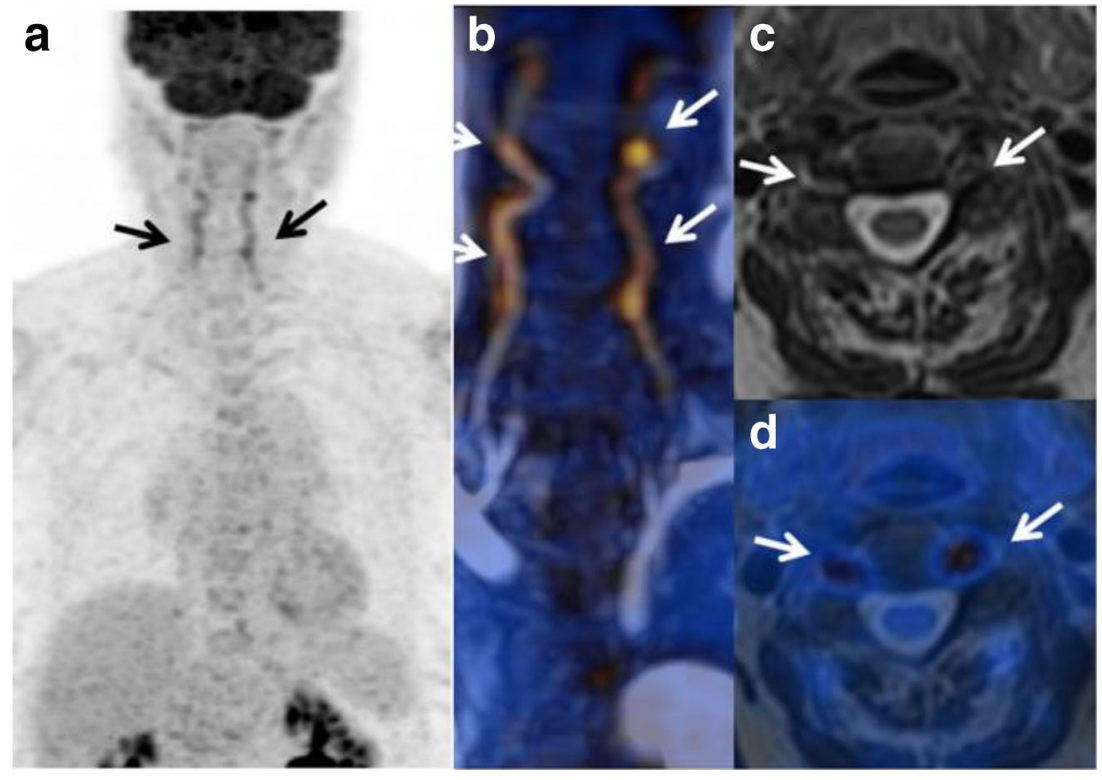

extracranial arteries remains visible in the majority of patients for months and years [71-73].

In large vessel GCA, IMT may be measured twice yearly [17]. If the treatment is effective, vasculitic wall thickening will become brighter and IMT decreases [74]. Low echogenicity and increasing wall thickness or new stenoses may indicate active disease. There are reports documenting resolution of the halo sign in the temporal arteries only 2 days after starting glucocorticoids; however, also a persistence of the halo sign for more than 6 months after treatment initiation has been observed [72]. In the temporal artery biopsy versus ultrasound in diagnosis of GCA (TABUL) study, a cross-

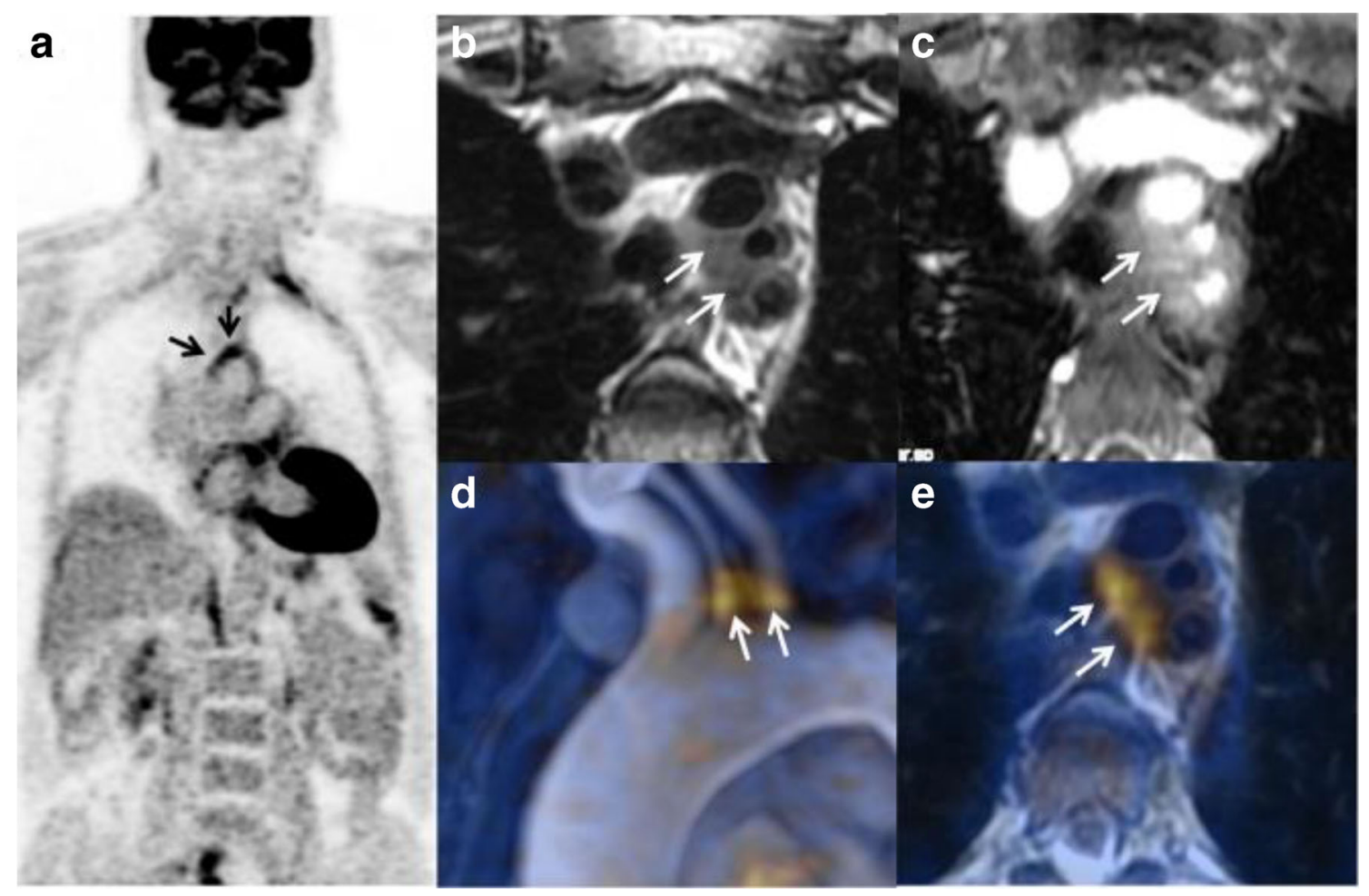

Fig. 6 PET / MRI in a patient with Takayasu arteritis. PET/MRI ((a) coronal PET, (b) T2-weighted image, (c) post-contrast T1-weighted image, (d) fusion MR angiography/PET, (e) fusion PET/T2-weighted image) shows an inflammatory pattern with clear uptake (grade 3 ) at the origin of supraaortic arteries associated with arterial wall thickening on T2-weighted image (a, arrows) and wall enhancement (b, arrows). Fusion images $(\mathbf{c}, \mathbf{d})$ show excellent co-registration of FDG uptake and MR findings. Laurent C et al. Sci Rep. 2019 Aug 27;9(1):12388 [63] published under a CC BY 4.0 license 
sectional analysis was performed on GCA patients with a halo sign in at least one branch of the temporal artery $(n=131)$ [14]. The halo size was smaller in patients who had already been treated with glucocorticoids for up to 7 days compared with patients without treatment of a very short time of treatment before the ultrasound examination [14, 72].

In TAK, serial measurements of the common carotid artery IMT have been proposed to assess response to treatment. Active lesions were found to have a mean IMT of $3.3 \pm$ $0.8 \mathrm{~mm}$ and inactive lesions of $1.6 \pm 0.4 \mathrm{~mm}$; in addition, increase of wall echogenicity has also been associated with decreased inflammation in TAK [72].

\section{Magnetic Resonance Imaging}

A retrospective study by Spira D et al. [75] suggested that contrast-enhanced MRA may be useful for monitoring disease activity in primary LVV with biological therapies, as the wall thickness significantly decreased at follow-up. Yet another study showed that MRI reveals vessel wall edema also in patients who were considered to be in clinical remission, suggesting that edema does not correlate with disease activity [20]. A more recent study assessing 20 patients with TAK prospectively found a statistically significant correlation between MRI features, including wall thickening and enhancement, suggesting active disease, as well as the Indian Takayasu activity score (ITAS) [76]. Another study found no statistically significant difference in MRI parameters in 30 patients with active TAK and 19 patients with inactive TAK [77].

A numerical damage index was developed and named as the Combined Arteritis Damage Score (CARDS). This index was derived from the following formula for 25 arterial regions: number of regions with mild stenosis $\times 0.6+$ number of regions with moderate to severe stenosis $\times 1.2+$ number of regions with occlusions $\times 1.6+$ number of regions with aneurysms $\times 0.8$ [78], which might help in future trials to standardize follow-up, at the moment lacking validation.

A recent study using delayed contrast-enhanced (DCE) MRI examined 27 patients with clinically active TAK compared with 12 patients with clinically inactive TAK and 27 age- and sex-matched healthy controls [79]. Neither stenosis nor delayed enhancement of arterial wall was shown in the control group. On MRI, delayed enhancement of arterial walls could be observed in the active TA group but not in the stable TA group or the control group. Authors therefore suggested that delayed enhancement on DCE-MRI is one characteristic of the active TA.

Commonly gadolinium-based contrast agents are used for MRA. Gadofosveset is a different contrast agent that might better differentiate between active and chronic vasculitis, as it does not enhance the fibrous tissue [80]. Further studies are needed to confirm the findings of this hypothesis.

\section{8-Fluorodeoxyglucose Positron Emission Tomography}

18FDG PET-CT is highly sensitive for the diagnosis of GCA and TAK, but due to radiation exposition, its application for follow-up in GCA and particularly in younger patients with TAK is limited. The data regarding whether FDG-PET can be used reliably to monitor treatment response and disease activity in LVV are less certain [81]. In a retrospective study [82], seven patients with an initial positive FDG-PET scan for LVV received repeated imaging to monitor treatment response. Four out of seven patients showed no FDG uptake on subsequent scans after an initial course of prednisolone therapy, suggesting that the use of FDG-PET in monitoring disease activity and treatment response may be appropriate in assisting prednisolone dose titration. Another study suggested that imaging acquisition time significantly influences reader interpretation of disease activity in PET scans performed in patients with LVV [83]; delayed imaging allows time for FDG distribution into the arterial wall with simultaneous elimination from blood pool [84]. Recent guidelines for FDG-PET assess at least $60 \mathrm{~min}$ and preferably $90 \mathrm{~min}[9,85]$. The role of 18F-FDG PET/CT for monitoring disease activity and guide treatment strategies is yet to be determined. Even though arterial FDG uptake rapidly decreases under glucocorticoid treatment, 18F-FDG PET/CT performed during the disease course shows persistent pathological arterial FDG uptake in the majority of patients, even in patients considered otherwise in clinical remission $[48,51,86]$. Remodeling or smoldering inflammation is thought to be possible explanations for this arterial metabolic activity. Serial PET scans during the disease course have reported a higher incidence of subsequent relapse among patients with high composite arterial PET scores (PETVAS) [48]. Also, PETVAS scores are inversely associated to preceding treatment changes [87].These findings support the hypothesis that persistent FDG uptake may reflect smoldering inflammatory activity, but data are still too scarce to establish specific criteria to guide treatment decisions.

\section{Computed Tomography/Computed Tomography Angiography}

Although widely used in the assessment of patients with TAK, there have been no reports comparing CTA with detailed assessment of disease activity in TAK. Sergio Prieto-González et al. [88] prospectively evaluated the outcome of CTA signs of large vessel inflammation and remodeling in GCA patients after approximately 1 year of glucocorticoid treatment. While contrast enhancement resolved in the majority of patients, vessel wall thickening persisted in two thirds. However, the number of affected aortic segments as well as aortic wall thickness significantly decreased. 


\section{Conclusion}

With the development of more sophisticated imaging technology, clinicians are provided with more and more imaging data. How to balance the advantages and disadvantages and master the indications of different imaging methods has become a must for rheumatologists.

As sign of vasculitis, US, MRI, and CT show a homogeneous arterial wall thickening, which is most commonly concentric. PET shows increased FDG uptake in inflammatory artery walls. US is recommended as the initial imaging modality in GCA, while MRI is recommended as the initial imaging modality in TAK; extracranial disease can be confirmed by all four modalities. In addition, MRI and PET/CT provide consistent and synchronized examination of the aorta and its branches. Imaging techniques have already gained an important role in the diagnosis LVV, while its role in monitoring has to be assessed in future trials. CEUS, PET/MRI, and other auxiliary methods such as "computer-assisted quantitative analysis" have emerged in the diagnosis and detection of diseases, giving a foundation for future research.

More prospective data on imaging techniques in GCA and TAK are needed, as well as on the role of imaging for outcome prediction and monitoring in LVV.

Funding Open Access funding enabled and organized by Projekt DEAL.

\section{Compliance with Ethical Standards}

Conflict of Interest The authors declare that they have no conflict of interest.

Human and Animal Rights and Informed Consent This article does not contain any studies with human or animal subjects performed by any of the authors.

Open Access This article is licensed under a Creative Commons Attribution 4.0 International License, which permits use, sharing, adaptation, distribution and reproduction in any medium or format, as long as you give appropriate credit to the original author(s) and the source, provide a link to the Creative Commons licence, and indicate if changes were made. The images or other third party material in this article are included in the article's Creative Commons licence, unless indicated otherwise in a credit line to the material. If material is not included in the article's Creative Commons licence and your intended use is not permitted by statutory regulation or exceeds the permitted use, you will need to obtain permission directly from the copyright holder. To view a copy of this licence, visit http://creativecommons.org/licenses/by/4.0/.

\section{References}

1. Stone JR, Bruneval P, Angelini A, Bartoloni G, Basso C, Batoroeva $\mathrm{L}$, et al. Consensus statement on surgical pathology of the aorta from the Society for Cardiovascular Pathology and the Association for European Cardiovascular Pathology: I. Inflammatory diseases. Cardiovasc Pathol. 2015;24(5):267-78. https://doi.org/10.1016/j.carpath.2015.05.001.
2. Furuta S, Cousins C, Chaudhry A, Jayne D. Clinical features and radiological findings in large vessel vasculitis: are Takayasu arteritis and giant cell arteritis 2 different diseases or a single entity? J Rheumatol. 2015;42(2):300-8. https://doi.org/10.3899/jrheum. 140562.

3. Kermani TA, Crowson CS, Muratore F, Schmidt J, Matteson EL, Warrington KJ. Extra-cranial giant cell arteritis and Takayasu arteritis: how similar are they? Semin Arthritis Rheum. 2015;44(6):724 8. https://doi.org/10.1016/j.semarthrit.2015.01.005.

4. Shima N, Nagashima T, Iwamoto M, Minota S. Comment on: retrospective analysis of 95 patients with large vessel vasculitis: a single center experience. Int J Rheum Dis. 2017;20(12):2211-3. https://doi.org/10.1111/1756-185X.12945.

5. Langford CA, Cuthbertson D, Ytterberg SR, Khalidi N, Monach PA, Carette S. Et al.a randomized, double-blind trial of abatacept (CTLA-4Ig) for the treatment of giant cell arteritis. Arthritis Rheum. 2017;69(4):837-45. https://doi.org/10.1002/art.40044.

6. Langford CA, Cuthbertson D, Ytterberg SR, Khalidi N, Monach PA, Carette S. Et al.a randomized, double-blind trial of abatacept (CTLA-4Ig) for the treatment of Takayasu arteritis. Arthritis Rheum. 2017;69(4):846-53. https://doi.org/10.1002/art.40037.

7. Gribbons KB, Ponte C, Carette S, Craven A, Cuthbertson D, Hoffman GS, et al. Patterns of arterial disease in Takayasu's arteritis and giant cell arteritis. Arthritis Care Res. 2019. https://doi.org/ 10.1002/acr.24055.

8. Luqmani R, Lee E, Singh S, Gillett M, Schmidt WA, Bradburn M, et al. The role of ultrasound compared to biopsy of temporal arteries in the diagnosis and treatmentof giant cell arteritis (TABUL): a diagnostic accuracy and cost-effectiveness study. Health Technol Assess. 2016;20(90):1-238.

9. Dejaco C, Ramiro S, Duftner C, Besson FL, Bley TA, Blockmans $\mathrm{D}$, et al. EULAR recommendations for the use of imaging in large vessel vasculitis in clinical practice. Ann Rheum Dis. 2018;77(5): 636-43. https://doi.org/10.1136/annrheumdis-2017-212649.

10. Patil P, Williams M, Maw WW, Achilleos K, Elsideeg S, Dejaco C, et al. Fast track pathway reduces sight loss in giant cell arteritis: results of a longitudinal observational cohort study. Clin Exp Rheumatol. 2015;33(2 Suppl 89):S-103-6.

11. Diamantopoulos AP, Haugeberg G, Lindland A, Myklebust G. The fast-track ultrasound clinic for early diagnosis of giant cell arteritis significantly reduces permanent visual impairment: towards a more effective strategy to improve clinical outcome in giant cell arteritis? Rheumatology (Oxford). 2016;55(1):66-70. https://doi.org/10. 1093/rheumatology/kev289.

12. Dejaco C, Duftner C, Buttgereit F, Matteson EL, Dasgupta B. The spectrum of giant cell arteritis and polymyalgia rheumatica: revisiting the concept of the disease. Rheumatology (Oxford). 2017;56(4):506-15. https://doi.org/10.1093/rheumatology/ kew273.

13. Prieto-González S, Arguis P, Cid MC. Imaging in systemic vasculitis. Curr Opin Rheumatol. 2015;27(1):53-62. https://doi.org/10. 1097/BOR.0000000000000130.

14. Monti S, Floris A, Ponte C, Schmidt WA, Diamantopoulos AP, Pereira $\mathrm{C}$, et al. The use of ultrasound to assess giant cell arteritis: review of the current evidence and practical guide for the rheumatologist. Rheumatology (Oxford). 2018;57(2):227-35. https://doi. org/10.1093/rheumatology/kex173.

15. Direskeneli H. Clinical assessment in Takayasu's arteritis: major challenges and controversies. Clin Exp Rheumatol. 2017;103(1): 189-93.

16. Sundholm JKM, Paetau A, Albäck A, Pettersson T, Sarkola T. Non-invasive vascular very-high resolution ultrasound to quantify artery intima layer thickness: validation of the four-line pattern. Ultrasound Med Biol. 2019;45(8):2010-8. https://doi.org/10. 1016/j.ultrasmedbio.2019.04.017. 
17. Schmidt WA. Ultrasound in the diagnosis and management of giant cell arteritis. Rheumatology (Oxford). 2018;57(suppl_2):ii22-31. https://doi.org/10.1093/rheumatology/kex461.

18. Schäfer VS, Juche A, Ramiro S, Krause A, Schmidt WA. Ultrasound cut-off values for intima-media thickness of temporal, facial and axillary arteries in giant cell arteritis. Rheumatology (Oxford). 2017;56(9):1632. https://doi.org/10.1093/rheumatology/ kex289.

19. Duftner C, Dejaco C, Sepriano A, Falzon L, Schmidt WA, Ramiro $\mathrm{S}$. Imaging in diagnosis, outcome prediction and monitoring of large vessel vasculitis: a systematic literature review and metaanalysis informing the EULAR recommendations. RMD Open. 2018;4(1):e000612. https://doi.org/10.1136/rmdopen-2017000612.

20. Nielsen BD, Gormsen LC, Hansen IT, Keller KK, Therkildsen P, Hauge EM. Three days of high-dose glucocorticoid treatment attenuates large-vessel 18F-FDG uptake in large-vessel giant cell arteritis but with a limited impact on diagnostic accuracy. Eur J Nucl Med Mol Imaging. 2018;45(7):1119-28. https://doi.org/10.1007/ s00259-018-4021-4

21. Lariviere D, Benali K, Coustet B, Pasi N, Hyafil F, Klein I, et al. Positron emission tomography and computed tomography angiography for the diagnosis of giant cell arteritis: a real-life prospective study. Medicine (Baltimore). 2016;95(30):e4146. https://doi.org/ 10.1097/MD.0000000000004146.

22. Yamada I, Nakagawa T, Himeno Y, Numano F, Shibuya H. Takayasu arteritis:evaluation of the thoracic aorta with CT angiography. Radiology. 1998;209(1):103-9.

23. Keser G, Aksu K. Diagnosis and differential diagnosis of largevessel vasculitides. Rheumatol Int. 2019;39(2):169-85. https:// doi.org/10.1007/s00296-018-4157-3.

24. Duftner C, Dejaco C, Sepriano A, Falzon L, Schmidt WA, Ramiro $\mathrm{S}$. Imaging in diagnosis, outcome prediction and monitoring of large vessel vasculitis: a systematic literature review and metaanalysis informing the EULAR recommendations. RMD Open. 2018;4(1):e000612. https://doi.org/10.1136/rmdopen-2017000612.

25. Yamada I, Nakagawa T, Himeno Y, Kobayashi Y, Numano F, Shibuya H. Takayasu arteritis: diagnosis with breath-hold contrast-enhanced three-dimensional MR angiography. J Magn Reson Imaging. 2000;11(5):481-7.

26. Sammel AM, Hsiao E, Schembri G, Nguyen K, Brewer J, Schrieber L, et al. Diagnostic accuracy of positron emission tomography/ computed tomography of the head, neck, and chest for giant cell arteritis: a prospective, double-blind. Cross-Sectional Study Arthritis Rheumatol. 2019;71(8):1319-28. https://doi.org/10.1002/ art.40864.

27. Chrysidis S, Duftner C, Dejaco C, Schäfer VS, Ramiro S, Carrara $\mathrm{G}$, et al. Definitions and reliability assessment of elementary ultrasound lesions in giant cell arteritis: a study from the OMERACT large vessel vasculitis ultrasound working group. RMD Open. 2018;4(1):e000598. https://doi.org/10.1136/rmdopen-2017000598.

28. Schäfer VS, Chrysidis S, Dejaco C, Duftner C, Iagnocco A, Bruyn GA, et al. Assessing vasculitis in giant cell arteritis by ultrasound: results of OMERACT patient-based reliability exercises. J Rheumatol. 2018;45(9):1289-95. https://doi.org/10.3899/jrheum. 171428.

29. Hop H, Mulder DJ, Sandovici M, Glaudemans AWJM, van Roon AM, Slart RHJA, et al. Diagnostic value of axillary artery ultrasound in patients with suspected giant cell arteritis. Rheumatology (Oxford). 2020;2:keaa102. https://doi.org/10.1093/rheumatology/ keaa102.

30. Nielsen BD, Hansen IT, Keller KK, Therkildsen P, Gormsen LC, Hauge EM. Diagnostic accuracy of ultrasound for detecting largevessel giant cell arteritis using FDG PET/CT as the reference.
Rheumatology (Oxford). 2019;6:kez568. https://doi.org/10.1093/ rheumatology/kez568.

31. Schmidt WA, Kraft HE, Völker L, Vorpahl K, Gromnica-Ihle EJ. Colour Doppler sonography to diagnose temporal arteritis. Lancet. 1995;345(8953):866.

32. De Miguel E, Beltran LM, Monjo I, Deodati F, Schmidt WA, Garcia-Puig J. Atherosclerosis as a potential pitfall in the diagnosis of giant cell arteritis. Rheumatology (Oxford). 2018;57(2):318-21. https://doi.org/10.1093/rheumatology/kex381.

33. Czihal M, Schröttle A, Baustel K, Lottspeich C, Dechant C, Treitl $\mathrm{KM}$, et al. B-mode sonography wall thickness assessment of the temporal and axillary arteries for the diagnosis of giant cell arteritis: A cohort study. Clin Exp Rheumatol. 2017;103(1):128-33.

34. Fernández-Fernández E, Monjo-Henry I, Bonilla G, Plasencia C, Miranda-Carús ME, Balsa A, et al. False positives in the ultrasound diagnosis of giant cell arteritis: some diseases can also show the halo sign. Rheumatology (Oxford). 2020;18:kez641. https://doi. org/10.1093/rheumatology/kez641.

35. Schmidt WA. The ultrasound halo sign of temporal arteries: is it always giant cell arteritis? Rheumatology (Oxford). 2019;58(11): 1898-9. https://doi.org/10.1093/rheumatology/kez355.

36. Ješe R, Rotar Ž, Tomšič M, Hočevar A. The role of colour doppler ultrasonography of facial and occipital arteries in patients with giant cell arteritis: a prospective study. Eur J Radiol. 2017;95:9-12. https://doi.org/10.1016/j.ejrad.2017.07.007.

37. Schmidt WA, Blockmans D. Investigations in systemic vasculitis the role of imaging. Best Pract Res Clin Rheumatol. 2018;32(1): 63-82. https://doi.org/10.1016/j.berh.2018.08.009.

38. Imfeld S, Aschwanden M, Rottenburger C, Schegk E, Berger CT, Staub D, et al. [18F]FDG positron emission tomography and ultrasound in the diagnosis of giant cell arteritis: congruent or complementary imaging methods? Rheumatology (Oxford). 2020;59(4): 772-8. https://doi.org/10.1093/rheumatology/kez362.

39. Maeda H, Handa N, Matsumoto M, Hougaku H, Ogawa S, Oku N, et al. Carotid lesions detected by B-mode ultrasonography in Takayasu's arteritis: "macaroni sign" as an indicator of the disease. Ultrasound Med Biol. 1991;17(7):695-701.

40. Barra L, Kanji T, Malette J, Pagnoux C. CanVasc. Imaging modalities for the diagnosis and disease activity assessment of Takayasu's arteritis: a systematic review and meta-analysis. Autoimmun Rev. 2018;17(2):175-87. https://doi.org/10.1016/j.autrev.2017.11.021.

41. Siemonsen S, Brekenfeld C, Holst B, Kaufmann-Buehler AK, Fiehler J, Bley TA. 3T MRI reveals extra- and intracranial involvement in giant cell arteritis. AJNR Am J Neuroradiol. 2015;36(1): 91-7. https://doi.org/10.3174/ajnr.A4086.

42. Treitl KM, Maurus S, Sommer NN, Kooijman-Kurfuerst H, Coppenrath E, Treitl M, et al. 3D-black-blood 3T-MRI for the diagnosis of thoracic large vessel vasculitis: a feasibility study. Eur Radiol. 2017;27(5):2119-28. https://doi.org/10.1007/s00330016-4525-x.

43. Schönau V, Vogel K, Englbrecht M, Wacker J, Schmidt D, Manger $\mathrm{B}$, et al. The value of (18)F-FDG-PET/CT in identifying the cause of fever of unknown origin (FUO) and inflammation of unknown origin (IUO): data from a prospective study. Ann Rheum Dis. 2018;77(1):70-7. https://doi.org/10.1136/annrheumdis-2017211687.

44. Nielsen BD, Hansen IT, Kramer S, Haraldsen A, Hjorthaug K, Bogsrud TV, et al. Simple dichotomous assessment of cranial artery inflammation by conventional 18F-FDG PET/CT shows high accuracy for the diagnosis of giant cell arteritis: a case-control study. Eur J Nucl Med Mol Imaging. 2019;46(1):184-93. https://doi.org/ 10.1007/s00259-018-4106-0.

45. Blockmans D, de Ceuninck L, Vanderschueren S, Knockaert D, Mortelmans L, Bobbaers H. Repetitive 18F-fluorodeoxyglucose positron emission tomography in giant cell arteritis: a prospective study of 35 patients. Arthritis Rheum. 2006;55(1):131-7. 
46. Bucerius J. Monitoring vasculitis with 18F-FDG PET. Q J Nucl Med Mol Imaging. 2016;60(3):219-35.

47. Hay B, Mariano-Goulart D, Bourdon A, Benkiran M, Vauchot F, De Verbizier D, et al. Diagnostic performance of (18)F-FDG PETCT for large vessel involvement assessment in patients with suspected giant cell arteritis and negative temporal artery biopsy. Ann Nucl Med. 2019;33(7):512-20. https://doi.org/10.1007/ s12149-019-01358-5.

48. de Boysson H, Aide N, Liozon E, Lambert M, Parienti JJ, Monteil $\mathrm{J}$, et al. Repetitive (18)F-FDG-PET/CT in patients with large-vessel giant-cell arteritis and controlled disease. Eur J Intern Med. 2017;46:66-70. https://doi.org/10.1016/j.ejim.2017.08.013.

49. Arnaud L, Haroche J, Malek Z, Archambaud F, Gambotti L, Grimon G, et al. Is (18)F-fluorodeoxyglucose positron emission tomography scanning a reliable way to assess disease activity in Takayasu arteritis? Arthritis Rheum. 2009;60(4):1193-200. https:// doi.org/10.1002/art.24416.

50. Sadeghi MM. (18)F-FDG PET and vascular inflammation: time to refine the paradigm? J Nucl Cardiol. 2015;22(2):319-24. https:// doi.org/10.1007/s12350-014-9917-1.

51. Grayson PC, Alehashemi S, Bagheri AA, Civelek AC, Cupps TR, Kaplan MJ, et al. (18)F-fluorodeoxyglucose-positron emission tomography as an imaging biomarker in a prospective, longitudinal cohort of patients with large vessel vasculitis. Arthritis Rheum. 2018;70(3):439-49. https://doi.org/10.1002/art.40379.

52. Pugliese F, Gaemperli O, Kinderlerer AR, Lamare F, Shalhoub J, Davies AH, et al. Imaging of vascular inflammation with [11C]PK11195 and positron emission tomography/computed tomography angiography. J Am Coll Cardiol. 2010;56(8):653-61. https:// doi.org/10.1016/j.jacc.2010.02.063.

53. Incerti E, Tombetti E, Fallanca F, Baldissera EM, Alongi P, Tombolini E, et al. (18)F-FDG PET reveals unique features of large vessel inflammation in patients with Takayasu's arteritis. Eur J Nucl Med Mol Imaging. 2017;44(7):1109-18. https://doi.org/10. 1007/s00259-017-3639-y.

54. Soussan M, Nicolas P, Schramm C, Katsahian S, Pop G, Fain O, et al. Management of large-vessel vasculitis with FDG-PET: a systematic literature review and meta-analysis. Medicine (Baltimore). 2015;94(14):e622. https://doi.org/10.1097/MD. 0000000000000622

55. de Boysson H, Dumont A, Liozon E, Lambert M, Boutemy J, Maigné G, et al. Giant-cell arteritis: concordance study between aortic CT angiography and FDG-PET/CT in detection of largevessel involvement. Eur J Nucl Med Mol Imaging. 2017;44(13): 2274-9. https://doi.org/10.1007/s00259-017-3774-5.

56. Hommada M, Mekinian A, Brillet PY, Abad S, Larroche C, Dhôte $\mathrm{R}$, et al. Aortitis in giant cell arteritis: diagnosis with FDG PET/CT and agreement with CT angiography. Autoimmun Rev. 2017;16(11):1131-7. https://doi.org/10.1016/j.autrev.2017.09.008.

57. Germanò G, Macchioni P, Possemato N, Boiardi L, Nicolini A, Casali M, et al. Contrast-enhanced ultrasound of the carotid artery in patients with large vessel vasculitis: correlation with positron emission tomography findings. Arthritis Care Res. 2017;69(1): 143-9. https://doi.org/10.1002/acr.22906.

58. Ma LY, Li CL, Ma LL, Cui XM, Dai XM, Sun Y, et al. Value of contrast-enhanced ultrasonography of the carotid artery for evaluating disease activity in Takayasu arteritis. Arthritis Res Ther. 2019;21(1):24. https://doi.org/10.1186/s13075-019-1813-2.

59. Misra R, Danda D, Rajappa SM, Ghosh A, Gupta R, Mahendranath $\mathrm{KM}$, et al. Development and initial validation of the Indian Takayasu clinical activity score (ITAS2010). Rheumatology (Oxford). 2013;52(10):1795-801. https://doi.org/10.1093/ rheumatology/ket128.

60. Lottspeich C, Dechant C, Köhler A, Tischler M, Treitl KM, Treitl $\mathrm{M}$, et al. Assessment of disease activity in Takayasu arteritis: potential role of contrast-enhanced ultrasound. Ultraschall Med. 2019;40(5):638-45. https://doi.org/10.1055/a-0817-5423.

61. Hu Y, Zhang Q, Li C. Computer-assisted quantitative analysis of contrast-enhanced ultrasonography in Takayasu arteritis carotid artery lesions. Sheng Wu Yi Xue Gong Cheng Xue Za Zhi. 2017;34(5):790-6. https://doi.org/10.7507/1001-5515.201702043.

62. Lad DP. Caution: PET-CT in plasma cell disorders. Lancet Haematol. 2020;7(2):e95. https://doi.org/10.1016/S2352-3026(19) 30263-7.

63. Laurent C, Ricard L, Fain O, Buvat I, Adedjouma A, Soussan M, et al. PET/MRI in large-vessel vasculitis: clinical value for diagnosis and assessment of disease activity. Sci Rep. 2019;9(1):12388. https://doi.org/10.1038/s41598-019-48709-w.

64. Einspieler I, Thürmel K, Pyka T, Eiber M, Wolfram S, Moog P, et al. Imaging large vessel vasculitis with fully integrated PET/MRI: a pilot study. Eur J Nucl Med Mol Imaging. 2015;42(7):1012-24. https://doi.org/10.1007/s00259-015-3007-8.

65. Einspieler I, Henninger M, Mergen V, Wendorff H, Haller B, Eiber $\mathrm{M}$, et al. Three-dimensional fat-saturated T1-weighted Cartesian volumetric interpolated breath-hold examination (VIBE) for the diagnosis of aortitis in patients with suspected large vessel vasculitis: a comparative study with (18)F-FDG PET applying fully integrated PET/MRI. Clin Radiol. 2019;74(9):731.e11-9. https://doi. org/10.1016/j.crad.2019.04.012.

66. Kermani TA, Cuthbertson D, Carette S, Hoffman GS, Khalidi NA, Koening CL, et al. Vasculitis clinical research consortium.The Birmingham vasculitis activity score as a measure of disease activity in patients with giant cell arteritis. J Rheumatol. 2016;43(6): 1078-84. https://doi.org/10.3899/jrheum.151063.

67. Kermani TA. Takayasu arteritis and giant cell arteritis: are they a spectrum of the same disease? Int J Rheum Dis. 2019;22(Suppl 1): 41-8. https://doi.org/10.1111/1756-185X.13288.

68. Sreih AG, Alibaz-Oner F, Kermani TA, Aydin SZ, Cronholm PF, Davis T, et al. Development of a core set of outcome measures for large-vessel vasculitis: report from OMERACT 2016. J Rheumatol. 2017;44(12):1933-7. https://doi.org/10.3899/jrheum.161467.

69. Ehlers L, Askling J, Bijlsma HW, Cid MC, Cutolo M, Dasgupta B, et al. 2018 EULAR recommendations for a core data set to support observational research and clinical care in giant cell arteritis. Ann Rheum Dis. 2019;78(9):1160-6. https://doi.org/10.1136/ annrheumdis-2018-214755.

70. Aydin SZ, Direskeneli H, Merkel PA. International Delphi on disease activity assessment in large-vessel vasculitis. assessment of disease activity in large-vessel vasculitis: results of an international Delphi exercise. J Rheumatol. 2017;44(12):1928-32. https://doi. org/10.3899/jrheum.161269.

71. Czihal M, Piller A, Schroettle A, Kuhlencordt P, Bernau C, Schulze-Koops H, et al. Impact of cranial and axillary/subclavian artery involvement by color duplex sonography on response to treatment in giant cell arteritis. J Vasc Surg. 2015 May;61(5): 1285-91. https://doi.org/10.1016/j.jvs.2014.12.045.

72. Germanò G, Monti S, Ponte C, Possemato N, Caporali R, Salvarani $\mathrm{C}$, et al. The role of ultrasound in the diagnosis and follow-up of large-vessel vasculitis: an update. Clin Exp Rheumatol. 2017;103(1):194-8.

73. Aschwanden M, Schegk E, Imfeld S, Staub D, Rottenburger C, Berger CT, et al. Vessel wall plasticity in large vessel giant cell arteritis: an ultrasound follow-up study. Rheumatology (Oxford). 2019;58(5):792-7. https://doi.org/10.1093/rheumatology/key383.

74. Monti S, Floris A, Ponte CB, Schmidt WA, Diamantopoulos AP, Pereira $\mathrm{C}$, et al. The proposed role of ultrasound in the management of giant cell arteritis in routine clinical practice. Rheumatology (Oxford). 2018;57(1):112-9. https://doi.org/10.1093/ rheumatology/kex341.

75. Spira D, Xenitidis T, Henes J, Horger M. MRI parametric monitoring of biological therapies in primary large vessel vasculitides: a 
pilot study. Br J Radiol. 2016;89(1058):20150892. https://doi.org/ 10.1259/bjr.20150892.

76. John RA, Keshava SN, Danda D. Correlating MRI with clinical evaluation in the assessment of disease activity of Takayasu's arteritis. Int J Rheum Dis. 2017;20(7):882-6. https://doi.org/10.1111/ 1756-185X.12967.

77. Kato Y, Terashima M, Ohigashi H, Tezuka D, Ashikaga T, Hirao $\mathrm{K}$, et al. Vessel wall inflammation of Takayasu arteritis detected by contrast-enhanced magnetic resonance imaging: association with disease distribution and activity. PLoS One. 2015;10(12): e0145855. https://doi.org/10.1371/journal.pone.0145855.

78. Nakagomi D, Cousins C, Sznajd J, Furuta S, Mohammad AJ, Luqmani R, et al. Development of a score for assessment of radiologic damage in large-vessel vasculitis (combined arteritis damage score, CARDS). Clin Exp Rheumatol. 2017;103(1):139-45.

79. Liu M, Liu W, Li H, Shu X, Tao X, Zhai Z. Evaluation of Takayasu arteritis with delayed contrast-enhanced MR imaging by a freebreathing 3D IR turbo FLASH. Medicine (Baltimore). 2017;96(51):e9284. https://doi.org/10.1097/MD. 0000000000009284 .

80. Papa M, De Cobelli F, Baldissera E, Dagna L, Schiani E, Sabbadini $\mathrm{M}$, et al. Takayasu arteritis: intravascular contrast medium for MR angiography in the evaluation of disease activity. AJR Am J Roentgenol. 2012;198(3):W279-84. https://doi.org/10.2214/AJR. 11.7360 .

81. Muratore F, Pipitone N, Salvarani C, Schmidt WA. Imaging of vasculitis: state of the art. Best Pract Res Clin Rheumatol. 2016;30(4):688-706. https://doi.org/10.1016/j.berh.2016.09.010.

82. Nguyen AD, Crowhurst T, Lester S, Dobson R, Bartholomeusz D, Hill C. The utility of fluorine-18-fluorodeoxyglucose positron emission tomography in the diagnosis and monitoring of large vessel vasculitis: a South Australian retrospective audit. Int J Rheum Dis. 2019;22(8):1378-82. https://doi.org/10.1111/1756-185X. 13617.

83. Quinn KA, Rosenblum JS, Rimland CA, Gribbons KB, Ahlman MA, Grayson PC. Imaging acquisition technique influences interpretation of positron emission tomography vascular activity in large-vessel vasculitis. Semin Arthritis Rheum. 2020;50(1):716. https://doi.org/10.1016/j.semarthrit.2019.07.008.

84. Bucerius J, Hyafil F, Verberne HJ, Slart RH, Lindner O, Sciagra R, et al. Position paper of the Cardiovascular Committee of the European Association of Nuclear Medicine (EANM) on PET imaging of atherosclerosis. Eur J Nucl Med Mol Imaging. 2016;43(4): 780-92. https://doi.org/10.1007/s00259-015-3259-3.

85. Slart RHJA, Writing group; Reviewer group; Members of EANM Cardiovascular; Members of EANM Infection \& Inflammation; Members of Committees, SNMMI Cardiovascular, et al. FDG$\mathrm{PET} / \mathrm{CT}(\mathrm{A})$ imaging in large vessel vasculitis and polymyalgia rheumatica: joint procedural recommendation of the EANM, SNMMI, and the PET Interest Group (PIG), and endorsed by the ASNC. Eur J Nucl Med Mol Imaging. 2018;45(7):1250-69. https:// doi.org/10.1007/s00259-018-3973-8.

86. Sammel AM, Hsiao E, Schembri G, Bailey E, Nguyen K, Brewer J, et al. Cranial and large vessel activity on positron emission tomography scan at diagnosis and 6 months in giant cell arteritis. Int $\mathrm{J}$ Rheum Dis. 2020;23(4):582-8. https://doi.org/10.1111/1756185X.13805.

87. Banerjee S, Quinn KA, Gribbons KB, Rosenblum JS, Civelek AC, Novakovich, et al. Effect of treatment on imaging, clinical, and serologic assessments of disease activity in large-vessel vasculitis. J Rheumatol. 2020;47(1):99-107. https://doi.org/10.3899/jrheum. 181222.

88. Prieto-González S, García-Martínez A, Tavera-Bahillo I, Hernández-Rodríguez J, Gutiérrez-Chacoff J, Alba MA, et al. Effect of glucocorticoid treatment on computed tomography angiography detected large-vessel inflammation in giant-cell arteritis. A prospective, longitudinal study. Medicine (Baltimore). 2015;94(5): e486. https://doi.org/10.1097/MD.0000000000000486.

Publisher's Note Springer Nature remains neutral with regard to jurisdictional claims in published maps and institutional affiliations. 